\title{
Potencial de aproveitamento energético de biogás através de reatores UASB: estudo de caso em Itaúna, Minas Gerais, Brasil
}

\section{Jonhson Herlich Roslee Mensah ${ }^{1}$, , Alessandra Ribeiro de Souza $^{1}$, Natalia de Souza Ribeiro', Lilian Carla Ferreira Freitas ${ }^{1}$, Alex Takeo Yasumura Lima Silva ${ }^{1}$ e Regina Mambeli Barros ${ }^{2}$}

${ }^{1}$ Universidade Federal de Itajubá (UNIFEI). Programa de Pós-Graduação em Engenharia de Energia. Avenida BPS, 1303. Pinheirinho. Itajubá-MG, Brasil (CEP 37500-903). *E-mail: mjherlich@gmail.com.

${ }^{2}$ Universidade Federal de Itajubá (UNIFEI). Instituto de Recursos Naturais. Avenida BPS, 1303. Pinheirinho. Itajubá-MG, Brasil (CEP 37500-903).

Resumo. Com o crescimento demográfico intensificou-se os problemas ambientais em decorrência do aumento na geração de efluentes líquidos. Desta forma torna-se fundamental a busca por alternativas sustentáveis na redução dos impactos. Neste cenário o presente trabalho tem como objetivo analisar o potencial energético e a viabilidade econômica do aproveitamento de biogás gerado em reator UASB no tratamento de efluentes originados pelo Município de Itaúna-MG, possibilitando o planejamento energético no período de 2018 a 2038. Estimou-se a projeção da população para este período e o dimensionamento do reator conforme as projeções de efluentes lançados. A produção média calculada de metano e de energia total produzida foi de 1.899,4 m $\mathrm{m}^{3} \mathrm{dia}^{-1}$ e 39,3 GWh, respectivamente. 0 investimento total necessário foi de $\mathrm{R} \$ 1.301 .508,53$, possibilitando a viabilidade econômica do projeto. A partir deste projeto é obtida a redução dos impactos ambientais consoante a geração de energia renovável.

Palavras-chave: Tratamento de efluentes líquidos; Reator UASB; Biogás; Aproveitamento energético.

Abstract. Potential of biogas energy use through UASB
reactors: Case study in Itaúna, Minas Gerais, Brasil. With
population growth intensified environmental problems as a result
of the increase in the generation of liquid effluents. In this way
becomes essential to the search for sustainable alternatives in
reducing impacts. In this scenario the present study aims to
analyze the energy potential and the economic feasibility of
biogas generated in UASB reactor in treatment of effluents caused
by the Municipality of Itaúna-MG, Brazil, enabling planning the
period 2018 energy to 2038 . It has been estimated the population

Recebido 10/04/2019

Aceito

13/11/2019

Disponível on line

13/11/2019

Publicado

31/12/2019

Acesso aberto

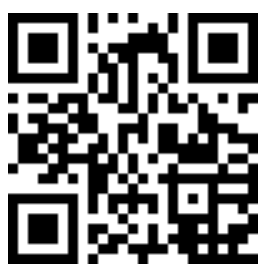

0000-0003-0897-892X Jonhson Herlich Roslee Mensah

D) 0000-0002-9346-4669 Alessandra Ribeiro de Souza 
projection for this period and scale of the reactor as the projections of effluent released. The calculated average production of methane and total energy produced, was 1899.4 $\mathrm{m}^{3}$.day-1 and $39.3 \mathrm{GWh}$, respectively. The total investment required was $R \$ 1,301,508.53$, enabling the economic viability of the project. From this, is the reduction of environmental impacts depending on the generation of renewable energy.

Keywords: Wastewater Treatment; UASB Reactor; Biogas; Energy Recovery.

\section{Introdução}

Os fatores como o crescimento populacional, a urbanização e o desenvolvimento tecnológico têm causado alterações tanto no estilo de vida como nos modos de produção e consumo da população (Gouveia, 2012). Além de se responsabilizar pelo acréscimo da produção de resíduos, o crescimento populacional também provoca o aumento dos problemas gerados ao meio ambiente como a poluição, a degradação dos recursos naturais, a contaminação do solo e das águas superficiais e subterrâneas.

De acordo com o relatório mundial das nações unidas sobre a valorização dos recursos hídricos (UN WATER, 2017), em média, os países de alta renda tratam cerca de $70 \%$ das águas residuais que geram, cuja proporção cai para $38 \%$ em países de renda média-alta e $28 \%$ nos países de renda média-baixa. Já nos países de baixa renda, apenas 8\% das águas residuais, industriais e municipais são tratadas. Nota-se que, no Brasil, somente $44,9 \%$ dos esgotos gerados são tratados (SNIS, 2018).

Uma das maneiras de tratar a água residuária é através da utilização de reatores anaeróbios de fluxo ascendente e manta de lodo - UASB (em inglês, Upflow Anaerobic Sludge Blanket), considerado um dos melhores processos de tratamento anaeróbio desenvolvidos até hoje (Stazi e Tomei, 2018). 0 uso
(ㄱ) $0000-0002-0749-1637$

Natalia de Souza

Ribeiro

D) 0000-0003-0687-1221

Lilian Carla Ferreira Freitas

D 0000-0003-1883-2414

Alex Takeo Yasumura Lima Silva

(ㄱ) 0000-0003-3154-2956

Regina Mambeli

Barros destes reatores para tratamento do esgoto doméstico tem se tornado cada vez mais comum especialmente em paises na América Latina e Índia (Rosa et al., 2018). De acordo com Chernicharo (2006), o uso de reatores anaeróbios é uma tecnologia consolidada em países quentes como o Brasil, onde praticamente todos os estudos de viabilidade de tratamento de efluentes incluem reatores anaeróbios como uma das principais opções.

Durante o processo de tratamento de esgoto, a digestão anaeróbia dos efluentes produz o biogás (Santos et al., 2016), um combustível renovável que pode ser usado para a producao de eletricidade, calor ou até mesmo como combustível para veículos (Scarlat et al., 2018). O biogás é composto principalmente por metano $\left(\mathrm{CH}_{4}\right)$ e dióxido de carbono $\left(\mathrm{CO}_{2}\right)$, dois gases altamente inflamáveis e energéticos (Von Sperling, 2005). Para a geração de energia a partir do biogás, o uso de reator UASB apresenta várias vantagens, em especial seu baixo custo de implantação e manutenção e sua função de preservar a qualidade do ar e da água (Silveira Filho et al., 2018). Consoante ao tratamento, o emprego desta técnica é muito eficiente, pois, após a retirada de uma quantidade elevada de carga orgânica por via anaeróbia, a geração de lodo em conjunto com a demanda de energia, passam a ser menores quando comparados aos 
processos aeróbios convencionais (Von Sperling, 2005).

Neste contexto, o presente trabalho propõe avaliar o potencial energético e a viabilidade econômica do aproveitamento de biogás gerado em reator UASB no tratamento de efluentes originados pela zona urbana do município de Itaúna, Minas Gerais, possibilitando o planejamento energético em um horizonte de 20 anos de projeto.

\section{Metodologia}

\section{Local de estudo}

O Município de Itaúna (latitude $22^{\circ} 04^{\prime} 30^{\prime \prime}$ Sul e longitude $44^{\circ} 34^{\prime} 33^{\prime \prime}$
Oeste) localiza-se no estado de Minas Gerais (MG), na microrregião de Divinópolis inserida na mesorregião do Oeste de Minas (Figura 1). Situado a 76 $\mathrm{km}$ da capital mineira de Belo Horizonte, apresenta uma área total de 495,7 km² e é limitado pelos municípios de Igaratinga e Pará de Minas ao norte, Mateus Leme a leste, Carmo de Cajuru a oeste e Itatiaiuçu ao sul. As principais atividades econômicas do município têm destaque nos setores de mineração e siderurgia (IBGE, 2010).

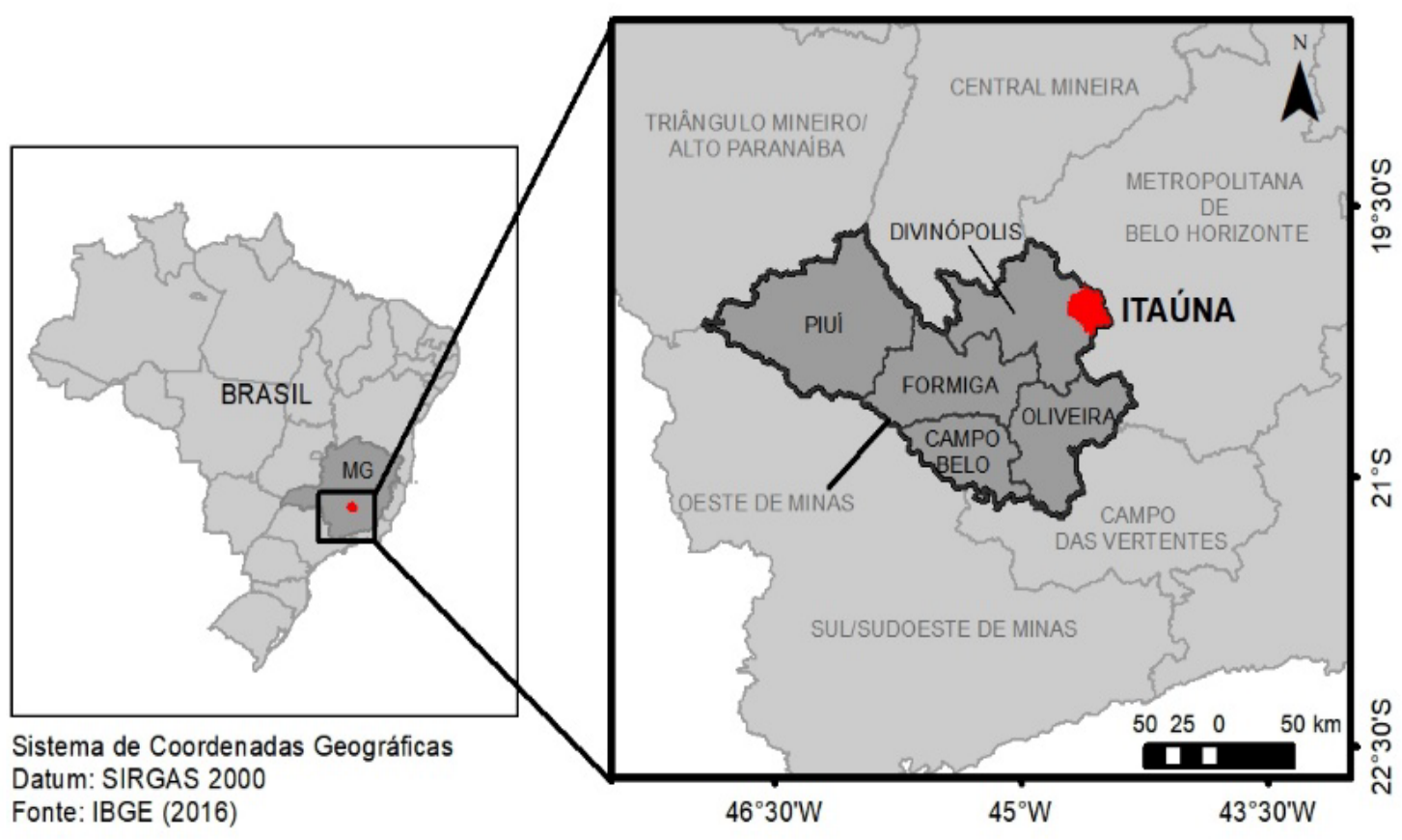

Figura 1. Localização do município de Itaúna-MG.

\section{Projeção populacional}

Nesta etapa, com base em dados históricos dos censos demográficos do Instituto Brasileiro de Geografia e Estatística (IBGE) (Tabela 1), estimou-se a projeção da população da área urbana do município, por ser geralmente atendida por Estação de Tratamento de Esgoto (ETE) para um período de 20 anos (2018 a 2038) por meio da projeção aritmética. Tal modelo foi selecionado após a realização de um estudo comparativo entre os resultados de diversos métodos de projeção 
disponíveis na literatura a fim de definir aquele que apresentou o resultado mais compatível com referência à estimativa populacional esperada pelo IBGE em 2017.

Tabela 1. População urbana de Itaúna (MG).

\begin{tabular}{lcc}
\hline \multicolumn{2}{l}{ Ano (t) } & População (P) \\
\hline $\mathbf{0}$ & 1991 & 61.946 \\
$\mathbf{1}$ & 2000 & 71.770 \\
$\mathbf{2}$ & 2010 & 80.451 \\
\hline
\end{tabular}

Fonte: IBGE (2010)

De acordo com Qasin (1999), a projeção populacional pelo método de projeção aritmética é dada através da Equação 1.

$$
P(t)=P_{0}+K_{a}\left(t-t_{0}\right)
$$

Onde:

$\mathrm{P}_{0}$ é o tamanho da população no tempo $\mathrm{t}=0$;

$\mathrm{K}_{\mathrm{a}}$ é a taxa de crescimento aritmética, calculada a partir da Equação 2:

$$
K_{a}=\ln \left[\frac{P_{0}\left(P_{s}-P_{1}\right)}{P_{1}\left(P_{s}-P_{0}\right)}\right] \frac{1}{\left(t_{2}-t_{1}\right)}
$$

Em que:

$\mathrm{P}_{1}$ é o tamanho da população no tempo $t=1$;

$P_{s}$ é o coeficiente de saturação, conforme obtido pela Equação 3.

$$
P_{s}=\frac{2 P_{0} P_{1} P_{2}-P_{1}^{2}\left(P_{0}+P_{2}\right)}{P_{0} P_{1}-P_{1}^{2}}
$$

\section{Projeção da produção de} efluentes de esgoto sanitário

A produção de esgotos foi calculada baseando-se na metodologia desenvolvida por Von Sperling (2005). Os parâmetros usados no cálculo foram: consumo médio per capita de 195 L.hab ${ }^{-1}$.dia-1 ${ }^{-1}$, segundo o Sistema Nacional de Informações sobre Saneamento (SNIS, 2017), e o coeficiente de retorno estimado em 80\%, conforme recomendado pela norma NBR 9649 (ABNT, 1986).

A estimativa das vazões de esgoto foi obtida por meio das Equações (4), (5) e (6).

$$
\begin{gathered}
Q_{\text {dom }}=\left(P_{a t} q C\right) / 1000 \\
Q_{\text {inf }}=T_{X} L \\
Q_{\text {total }}=Q_{\text {dom }}+Q_{\text {inf }}
\end{gathered}
$$

Onde:

$\mathrm{Q}_{\mathrm{dom}}=$ vazão doméstica média $\left(\mathrm{m}^{3}\right.$.dia $\left.{ }^{-1}\right)$;

$\mathrm{Q}_{\text {inf }}=$ vazão de infiltração $\left(\mathrm{m}^{3}\right.$.dia1);

$\mathrm{Q}_{\text {total }}=$ vazão total média a ser tratada $\left(\mathrm{m}^{3}\right.$.dia $\left.{ }^{-1}\right)$;

$\mathrm{P}_{\mathrm{at}}=$ população atendida (hab);

$\mathrm{T}_{\mathrm{x}}=$ taxa de infiltração

(L.s ${ }^{-1} \cdot \mathrm{km}^{-1}$ ), valor adotado de 0,3 ;

$\mathrm{q}=$ taxa de consumo per capita

(l.hab ${ }^{-1} \cdot$ dia $^{-1}$ );

$\mathrm{C}=$ coeficiente de retorno $(\%)$.

$\mathrm{Na}$ parcela total de vazão a ser tratada não foi contabilizada à geração de efluentes industriais, assumindo que os grandes estabelecimentos produtores são dotados de estações de tratamento e tecnologias próprias para garantir o descarte final ambientalmente adequado.

Para fins de dimensionamento do reator UASB, calculou-se, ainda, a vazão doméstica máxima, multiplicando-se $Q_{\text {dom }}$ média obtida na Equação 4 pelo coeficiente proveniente da razão entre $Q_{\text {dom }}$ máxima e $Q_{\text {dom }}$ média segundo a fórmula de Harmon (Von Sperling, 2005), Equação 7.

$$
Q_{\text {dom }_{\text {max }}} / Q_{\text {dom }_{\text {med }}}=1+\frac{14}{4+\sqrt{P_{a t}}}
$$

A vazão total máxima é obtida consequentemente pela aplicação da Equação 6. 
$\mathrm{Na}$ determinação da população atendida pelo tratamento de esgotos, considerou-se a população urbana projetada a cada cinco anos, contada a partir de 2018, em função do índice de atendimento de esgotamento sanitário. Adotou-se um índice de atendimento de $100 \%$ nas estimativas uma vez que, de acordo o SNIS (2017), o índice foi de quase $100 \%$ em 2016.

Para a definição da vazão de infiltração, multiplicou-se a taxa de infiltração por um índice de extensão da rede de coleta de esgotos por habitante atendido, sendo este calculado de acordo com dados de população e extensão de rede de coleta obtidos no SNIS (2017). Estimou-se, assim, uma extensão média de rede de 0,00423 km.hab-1 em Itaúna entre os anos de 2011 e 2016.

A carga de DBO total presente no esgoto gerado pode ser estimada em cada ano através da Equação 8.

$$
C_{D B O_{\text {total }}}=C_{D B O_{\text {dom }}}+C_{D B O_{\text {inf }}}=\frac{P_{a t} .50}{1000}
$$

Onde:

$$
\mathrm{C}_{\mathrm{DBO}} \text { total }=\text { carga total de } \mathrm{DBO}
$$

(kg.dia-1); $\left(\mathrm{kg}^{- \text {dia }^{-1}}\right)$;

$$
\mathrm{C}_{\mathrm{DBO}_{\mathrm{dom}}}=\text { carga de } \mathrm{DBO} \text { doméstica }
$$

$\mathrm{C}_{\mathrm{DBO}_{\text {inf }}}=$ carga de $\mathrm{DBO}$ de infiltração (kg.dia-1 $\left.{ }^{-1}\right)$.

De acordo com a Equação 8, ressalta-se que o cálculo da DBO total se refere à parcela de DBO doméstica, adotando-se uma carga orgânica diária per capita de 50 g DBO.hab ${ }^{-1} \cdot$ dia $^{-1}$ e considerando-se nulo o valor de DBO pelas águas de infiltração considera-se.

A carga total de DQO, por sua vez, é definida a partir da relação DQO/DBO equivalente a 2,05, considerando que, segundo Von Sperling (2005), a mesma relação varia em torno de 1,7 a 2,4 para esgotos domésticos brutos.

Por fim, é possível determinar a concentração total de DBO e DQO dos esgotos afluentes à ETE $\left(\mathrm{S}_{0}\right)$, em mg.L-1 dados através do quociente entre a carga total de DBO ou de DQO, em kg.dia-1, e a vazão média de esgotos, em $\mathrm{m}^{3} \cdot$ dia $^{-1}$, conforme Equações 9 e 10.

$$
\begin{aligned}
& S_{0}=\frac{C_{D B O_{\text {total }}}}{Q_{\text {total }}} 1000 \\
& S_{0}=\frac{C_{D Q O_{\text {total }}}}{Q_{\text {total }}} 1000
\end{aligned}
$$

\section{UASB \\ Dimensionamento do reator}

O dimensionamento do reator foi realizado segundo a metodologia proposta por Chernicharo (2011), baseando-se nos valores estimados de vazão e carga orgânica de final de plano (ano de 2038). O volume do reator é dado pela Equação 11.

$$
V=Q_{\text {med }} t
$$

Onde:

$\mathrm{V}=$ volume total do reator $\left(\mathrm{m}^{3}\right)$;

$\mathrm{Q}_{\text {med }}=$ vazão média do esgoto afluente $\left(\mathrm{m}^{3} \cdot \mathrm{h}^{-1}\right)$;

$\mathrm{t}=$ tempo de detenção hidráulica (h).

Nota-se que o tempo de detenção hidráulico médio é um fator importante no cálculo do volume total de reatores. Segundo Chernicharo (2011), para esgotos domésticos sendo tratados na faixa de temperatura $20^{\circ} \mathrm{C}$ e $26^{\circ} \mathrm{C}$, temse adotado tempos de detenção hidráulica da ordem de 6 a 10 horas. Assim, considerou-se para o presente estudo o tempo médio de $8 \mathrm{~h}$.

A velocidade superficial média recomendada para o projeto de UASB, tratando esgotos domésticos, deve ser da ordem de 0,5 a $0,7 \mathrm{~m} \cdot \mathrm{h}^{-1}$ para vazões médias e de 0,9 a $1,1 \mathrm{~m} \cdot \mathrm{h}^{-1}$ para vazões máximas, sendo calculada pela Equação 12. 


$$
v=Q / A
$$

Na qual:

$\mathrm{v}=$ velocidade superficial do fluxo, ou velocidade ascensional $\left(\mathrm{m} \cdot \mathrm{h}^{-1}\right)$;

$\mathrm{Q}=$ vazão média ou máxima do esgoto afluente $\left(\mathrm{m}^{3} \cdot \mathrm{h}^{-1}\right)$;

$\mathrm{A}=$ área da seção transversal do reator $\left(\mathrm{m}^{2}\right)$.

A estimativa da eficiência de reatores UASB é usualmente realizada por meio de relações empíricas, obtidas a partir de resultados experimentais de reatores em operação. Para o tempo de detenção hidráulica de 8 horas, esperamse eficiências aproximadas de remoção de DQO e DBO de, respectivamente, $67 \%$ e $75 \%$ para esgotos brutos com temperatura entre $20{ }^{\circ} \mathrm{C}$ e $27{ }^{\circ} \mathrm{C}$ e faixa de concentração de DQO e DBO de, respectivamente, 300-1.400 mg.L $\mathrm{L}^{-1}$ e 150-850 mg.L-1 (Chernicharo, 2011). Assim, a partir das eficiências esperadas para o sistema, pode-se estimar as concentrações de DQO e de DBO no efluente final, Equação 13.

$$
S=S_{0}-\frac{E \cdot S_{0}}{100}
$$

Em que:

$\mathrm{S}=$ concentração média de DQO ou de DBO efluente (mg. $\mathrm{L}^{-1}$ );

$\mathrm{S}_{0}=$ concentração média de DBO ou de DBO afluente (mg.L $\mathrm{L}^{-1}$ );

$\mathrm{E}=$ eficiência de remoção do processo (\%).

\section{Estimativa da produção de metano e seu potencial energético}

A produção de metano do biogás foi calculada segundo Chernicharo (2011) a partir da estimativa da carga de DQO afluente ao reator que é convertida em gás metano $\left(\mathrm{CH}_{4}\right) \mathrm{A}$ determinação da parcela de DQO convertida, em termos de massa, pode ser feita segundo a Equação 14.

$$
D Q O_{C_{4}}=Q_{\text {med }}\left(S_{0}-S\right)-Y_{o b s} Q_{m e d} S_{0}
$$

Onde:

$\mathrm{DQO}_{\mathrm{CH}_{4}}=$ carga de DQO convertida em metano $\left(\mathrm{kgDQO}_{\mathrm{CH} 4} \cdot \mathrm{dia}^{-1}\right)$;

$\mathrm{Q}_{\text {med }}=$ vazão média do esgoto afluente $\left(\mathrm{m}^{3}\right.$.dia $\left.{ }^{-1}\right)$;

$\mathrm{S}_{0}=$ concentração de DQO afluente (kgDQO. $\mathrm{m}^{-3}$ );

$\mathrm{S}=$ concentração de DQO efluente (kgDQO. $\mathrm{m}^{-3}$ );

$Y_{\text {obs }}=$ coeficiente de produção de sólidos no sistema, em termos de DQO $\left(0,11\right.$ a $0,23 \mathrm{kgDQO}_{\text {lodo. }} . \mathrm{kgDQO}_{\text {aplicado }^{-1}}{ }^{-1}$.

A produção volumétrica de metano $\left(\mathrm{Q}_{\mathrm{CH}_{4}}\right)$, em $\mathrm{m}^{3}$.dia-1, é então determinada pela Equação 15.

$$
Q_{\mathrm{CH}_{4}}=\frac{\mathrm{DQO}_{\mathrm{CH}_{4}}}{f(\mathrm{~T})}
$$

Sendo $f(T)$ o fator de correção para a temperatura operacional do reator, em $\mathrm{kgDQO} . \mathrm{m}^{-3}$, determinado pela Equação 16.

$$
f(T)=\frac{P \cdot K_{D Q O}}{R(273+T)}
$$

Onde:

$\mathrm{P}$ = pressão atmosférica (1 atm);

$\mathrm{K}_{\mathrm{DQO}}=\mathrm{DQO}$ correspondente a um mol de $\mathrm{CH}_{4}$ (64 gDQO.mol-1);

$\mathrm{R}=$ constante universal dos gases $\left(0,08206\right.$ atm.L.mol-1 $\left.{ }^{-1} \mathrm{~K}^{-1}\right)$;

$\mathrm{T}=$ temperatura operacional do reator $\left({ }^{\circ} \mathrm{C}\right)$

A partir da vazão estimada de metano, é possível determinar a potência total disponível considerando o poder calorífico do metano igual a 35.530 $\mathrm{kJ} . \mathrm{m}^{-3} \mathrm{CH}_{4}$ (modificado de CETESB, 2006), Equação 17.

$$
P=\frac{Q_{\mathrm{CH}_{4}} P C_{\mathrm{CH}_{4}}}{86400}
$$


No qual:

$\mathrm{P}=$ potência disponível $(\mathrm{kW})$;

$\mathrm{Q}_{\mathrm{CH}_{4}}=$ vazão de metano

$\left(\mathrm{m}^{3} \cdot \mathrm{dia}^{-1}\right)$;

$\mathrm{PC}_{\mathrm{CH}_{4}}=$ poder calorífico do

metano $\left(\mathrm{kJ} \cdot \mathrm{m}^{-3} \mathrm{CH}_{4}\right)$;

$86.400=$ número de segundos em 1 dia $\left(\right.$ s.dia $\left.^{-1}\right)$.

A potência útil elétrica, por sua vez, é definida em função da multiplicação entre a potência disponível, a eficiência de conversão de biogás para energia elétrica de $33 \%$ e a eficiência de queima do biogás de 95\%, conforme valores sugeridos por CETESB (2006).

\section{Análise da viabilidade econômica}

A análise de viabilidade econômica do aproveitamento energético de biogás foi realizada para um horizonte de 20 anos, correspondendo ao período de 2018 a 2038. Com a análise dos resultados de potencial energético obtidos na etapa anterior, considerou-se uma central com instalação de um motor com $270 \mathrm{~kW}$ de capacidade de geração, capaz de atender a potência útil gerada pelo gás em todo horizonte de projeto, de modo a evitar a troca dos motores devido ao aumento da potência útil gerada pelo tratamento em reator UASB ao longo dos anos.

0 indicador econômico utilizado foi o Valor Presente Líquido (VPL), em que apresenta os valores futuros do benefício líquido. Assim, as receitas do empreendimento subtraídas dos custos de operação são corrigidas por uma taxa de juros, conforme Equação 18, devendo o resultado ser superior a zero para indicar a viabilidade do empreendimento (Rodrigues e Melo, 2017).

$$
V P L=\sum_{j=0}^{n} \frac{R_{j}-C_{j}}{(1+i)^{j}}-I
$$

Onde:

$\mathrm{Rj}=$ receitas do período $\mathrm{j} ;$

$\mathrm{Cj}=$ custos do período $\mathrm{j}$;

$\mathrm{i}=$ taxa de juros;

$\mathrm{I}=$ investimento inicial.

A taxa de juros adotada para a análise foi a taxa SELIC, cujo valor foi de $6,4 \%$ no dia 11/06/2018 conforme BACEN (2018). O custo de implantação da central baseou-se em Santos et al. (2016) e CETESB (2006), descritos a seguir:

- Custo do gasômetro: 60 US\$.m ${ }^{-3}$, dimensionado para $6,7 \%$ do volume máximo de biogás gerado diariamente em 2038;

- Custo do queimador: 20.321,35 $\mathrm{R} \$$.unidade ${ }^{-1}$, sendo adotado apenas uma unidade;

- Custo do compressor: 565 US\$. $\mathrm{m}^{-3}$.hora ${ }^{-1}$;

- Custo dos motores: 510 US\$.kW-1.

Para a conversão da moeda para reais, adotou-se o câmbio do dia $28 / 05 / 2016$, cujo valor é de $\mathrm{R} \$ 3,709$ (BACEN, 2018). Adotou-se o contexto de aplicação da Resolução Normativa $\mathrm{n}^{\mathrm{o}}$ 482/2012 (ANEEL, 2012) e sua revisão, a Resolução Normativa no 687/2015 (ANEEL, 2015), considerando o valor da tarifa de venda de energia de 509,74 $\mathrm{R}$ \$.MWh ${ }^{-1}$ apresentada na Associação Brasileira de Distribuidores de Energia Elétrica (ABRADEE), pela CEMIG Distribuidora, entre 8 de abril de 2015 a 7 de abril de 2016. Considerou-se, ainda, o custo de manutenção como sendo de $10 \%$ do seu custo de implantação, bem como a substituição dos motores a cada 8 anos de operação, uma vez que as impurezas contidas no gás causam o seu desgaste prematuro (Santos et al., 2016). A eficiência dos motores adotada foi de $50 \%$ e o fator de capacidade da central de $60 \%$, considerando também que não houve operação no ano 0 devido à instalação e à preparação do aproveitamento. 


\section{Resultados}

\section{Projeção populacional}

Tendo em vista o período de interesse (2018 a 2038), segundo os cálculos pela projeção aritmética, a população urbana de Itaúna cresce de 88.243 habitantes em 2018, passando para 107.722 habitantes em 2038, considerando uma população de saturação de 108.352 habitantes. A tendência de crescimento populacional foi positiva para o município, correspondente a uma taxa de crescimento anual de $1 \%$. Os valores obtidos pela projeção populacional estão representados na Figura 3.

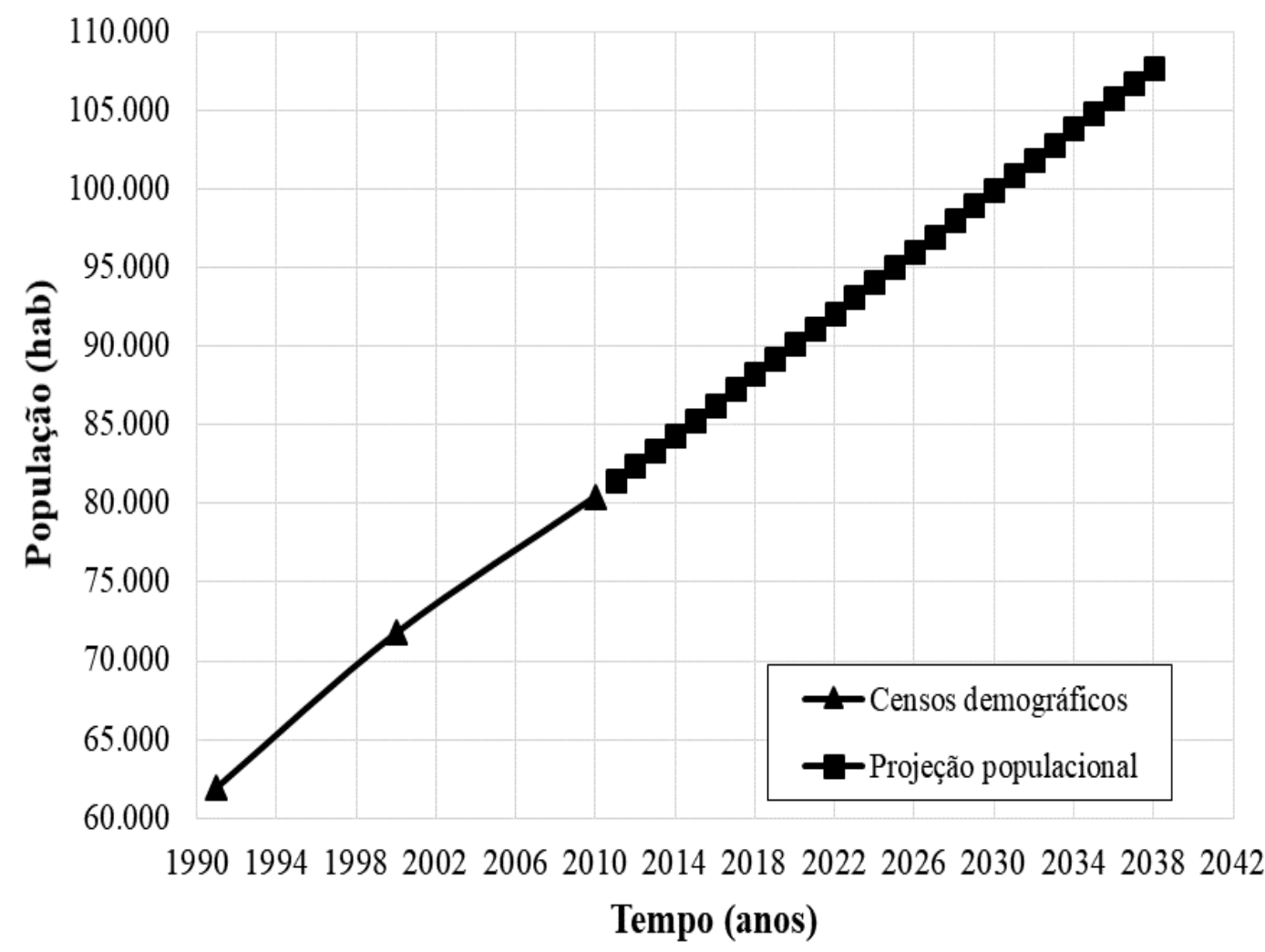

Figura 3. Projeção populacional para o município de Itaúna-MG no período entre 2018 e 2038.

Projeção da produção de efluentes e esgoto sanitário

A partir dos dados de população urbana, foi possível definir os valores dos parâmetros de entrada no cálculo da produção de efluentes e esgoto sanitário considerando o índice de atendimento e a extensão da rede coletora de esgotos (Tabela 2). 
Tabela 2. Valores dos parâmetros de entrada para determinação das vazões de esgoto em ItaúnaMG.

\begin{tabular}{lcccc}
\hline Ano & $\begin{array}{c}\text { População } \\
\text { urbana (hab) }\end{array}$ & $\begin{array}{c}\text { Índice de } \\
\text { atendimento (\%) }\end{array}$ & $\begin{array}{c}\text { População } \\
\text { atendida (hab) }\end{array}$ & $\begin{array}{c}\text { Extensão da rede } \\
\text { (km) }\end{array}$ \\
\hline $\mathbf{2 0 1 8}$ & 88.243 & 100 & 88.243 & 373,3 \\
$\mathbf{2 0 2 3}$ & 93.112 & 100 & 93.112 & 393,9 \\
$\mathbf{2 0 2 8}$ & 97.982 & 100 & 97.982 & 414,5 \\
$\mathbf{2 0 3 3}$ & 102.852 & 100 & 102.852 & 435,1 \\
$\mathbf{2 0 3 8}$ & 107.722 & 100 & 107.722 & 455,7 \\
\hline
\end{tabular}

A Tabela 3 apresenta as vazões de esgoto estimadas no período em análise, juntamente com as cargas diárias de DBO e DQO. 0 valor de vazão média de
28.615,4 $\mathrm{m}^{3}$.dia ${ }^{-1}$ em 2038, isto é, em final de plano, será utilizado para o dimensionamento do reator UASB.

Tabela 3: Vazões de esgoto e cargas de DBO e DQO estimadas para Itaúna-MG.

\begin{tabular}{|c|c|c|c|c|c|}
\hline Ano & $\begin{array}{c}\text { Vazão } \\
\text { doméstica } \\
\left(\mathrm{m}^{3} \cdot \text { dia }^{-1}\right)\end{array}$ & $\begin{array}{c}\text { Vazão de } \\
\text { infiltração } \\
\left(\mathrm{m}^{3} \cdot \text { dia }^{-1}\right)\end{array}$ & $\begin{array}{l}\text { Vazão total } \\
\left(\mathrm{m}^{3} \cdot \mathrm{dia}^{-1}\right)\end{array}$ & $\begin{array}{l}\text { Carga de DBO } \\
\left(\text { kg.dia }^{-1}\right)\end{array}$ & $\begin{array}{c}\text { Carga de DQO } \\
\quad \text { (kg.dia }^{-1} \text { ) }\end{array}$ \\
\hline 2018 & $13.765,9$ & $9.675,1$ & $23.441,0$ & $4.412,2$ & $9.044,9$ \\
\hline 2023 & $14.525,5$ & $10.208,9$ & $24.734,4$ & $4.655,6$ & $9.544,0$ \\
\hline 2028 & $15.285,2$ & $10.742,9$ & $26.028,1$ & $4.899,1$ & $10.043,2$ \\
\hline 2033 & $16.044,9$ & $11.276,9$ & $27.321,8$ & $5.142,6$ & $10.542,3$ \\
\hline 2038 & $16.804,6$ & $11.810,8$ & $28.615,4$ & $5.386,1$ & $11.041,5$ \\
\hline
\end{tabular}

No último ano, a carga orgânica diária é de 5.386,1 kgDBO.dia ${ }^{-1}$, equivalente a uma carga de 11.041,5 kgDQO.dia ${ }^{-1}$. Em todo o período de interesse, tais cargas correspondem a concentrações de DBO e DQO afluentes aos reatores UASB de, respectivamente, 188,2 mg. $\mathrm{L}^{-1}$ e 385,9 mg.L $\mathrm{L}^{-1}$. Em termos de remoção de DQO, com $67 \%$ de eficiência, a concentração do efluente final é de 127,3 mg.L $\mathrm{L}^{-1}$. Os valores de concentrações médias de DQO para os esgotos afluentes e efluentes são, por sua vez, fundamentais para posterior estimativa do potencial energético do biogás gerado pelo reator UASB.

\section{UASB}

\section{Dimensionamento do reator}

Com base nos valores de vazão média de esgotos de 28.615,4 $\mathrm{m}^{3}$.dia ${ }^{-1}$ para a população estimada no ano de
2038, bem como no tempo de detenção hidráulico adotado de 8 horas, o reator UASB projetado para o município de Itaúna apresenta um volume teórico total de $9.538,5 \mathrm{~m}^{3}$. Adotando-se 16 reatores, o volume de cada tanque é de $596,2 \mathrm{~m}^{3}$.

Segundo Chernicharo (2011), para as velocidades superficiais e os tempos de detenção hidráulica recomendados para o projeto de reatores UASB tratando esgotos domésticos, as alturas dos reatores devem ficar compreendidas entre 3 e $6 \mathrm{~m}$. Em função da adequação das velocidades de fluxo superficial dentro dos limites recomendados, adotou-se uma altura útil de $5 \mathrm{~m}$, resultando em uma área de 119,2 $\mathrm{m}^{2}$ para cada reator e velocidades ascensionais de $0,62 \mathrm{~m} \cdot \mathrm{h}^{-1}$ para a vazão média e $0,98 \mathrm{~m} \cdot \mathrm{h}^{-1}$ para a vazão máxima. Optou-se por considerar, por fim, um sistema de 4 módulos compostos por 4 
reatores UASB de seção transversal retangular, com dimensões laterais de 6,0 x 19,9 m (maior facilidade para fins construtivos) e $597 \mathrm{~m}^{3}$ de volume cada, sendo cada módulo capaz de tratar uma vazão de esgoto de $7.153,9 \mathrm{~m}^{3} \cdot \mathrm{dia}^{-1}$.

\section{Estimativa da produção de metano e potencial energético}

A estimativa da produção volumétrica de metano e consequente determinação do potencial energético, segundo a metodologia adotada, baseia- se na carga de DQO afluente ao reator UASB. Para os cálculos, considerou-se um coeficiente médio de produção de sólidos no sistema de 0,17 $\mathrm{kgDQO}_{\text {lodo. }} \cdot \mathrm{kgDQO}_{\text {aplicado }^{-1}}{ }^{-1}$, sendo o fator de correção $\mathrm{f}(\mathrm{T})$ estimado em 2,64 kgDQ0. $\mathrm{m}^{-3}$ para uma temperatura média operacional de $22{ }^{\circ} \mathrm{C}$ em Itaúna. Com base nesses valores, determinou-se a geração de metano e o potencial energético ao longo do período de estudo, conforme Tabela 4.

Tabela 4. Produção volumétrica de metano e potências disponível e útil em função das vazões médias de esgoto tratado em Itaúna-MG no período de 2018 a 2038.

\begin{tabular}{|c|c|c|c|c|}
\hline Ano & $\begin{array}{l}\text { Vazão total } \\
\left(\mathbf{m}^{3} \cdot \text { dia }^{-1}\right)\end{array}$ & $\begin{array}{c}\text { Produção de } \\
\text { metano }\left(\mathrm{m}^{3} \cdot \text { dia }^{-1}\right)\end{array}$ & $\begin{array}{c}\text { Potência } \\
\text { disponível [kW] }\end{array}$ & $\begin{array}{l}\text { Potência útil } \\
{[\mathrm{kW}]}\end{array}$ \\
\hline 2018 & $23.441,0$ & $1.710,6$ & 703 & 221 \\
\hline 2023 & $24.734,4$ & $1.805,0$ & 742 & 233 \\
\hline 2028 & $26.028,1$ & $1.899,4$ & 781 & 245 \\
\hline 2033 & $27.321,8$ & $1.993,8$ & 820 & 257 \\
\hline 2038 & $28.615,4$ & $2.088,2$ & 859 & 269 \\
\hline
\end{tabular}

A vazão média de metano ao longo dos anos em análise é de 1.899,4 $\mathrm{m}^{3}$.dia ${ }^{-1}$, passando de $1.710,6 \mathrm{~m}^{3} \cdot \mathrm{dia}^{-1} \mathrm{em}$ 2018 para 2.088,2 $\mathrm{m}^{3}$. $\mathrm{dia}^{-1}$ em 2038. Segundo Chernicharo (2011), para o caso de tratamento de esgotos domésticos, os teores de metano no biogás são usualmente da ordem de $70 \%$ a $80 \%$. Considerando-se um teor de 75\%, a vazão média do biogás no período em estudo seria de $2.532,5 \mathrm{~m}^{3}$.dia-1 .

Em relação aos cálculos energéticos, é possível observar que a potência teórica disponível para aproveitamento energético foi de 703 $\mathrm{kW}$ no primeiro ano, passando para 859 kW em 2038. Na prática, no entanto, ao se considerar o rendimento da tecnologia de conversão e a capacidade de aproveitamento do biogás, o valor teórico reduz para $221 \mathrm{~kW}$ em 2018, alcançando $269 \mathrm{~kW}$ em 20 anos. Ao considerar uma usina com tempo de operação de 22 horas por dia, valor conforme indicado por CETESB (2006), a quantidade de energia anual a ser produzida aumentaria de 1,7 GWh.ano-1 em 2018 para 2,2 GWh.ano-1 em 2038. Durante o período em análise, a energia total média a ser produzida seria de 39,3 GWh.

\section{econômica \\ Análise da viabilidade \\ Para o aproveitamento de 270} $\mathrm{kW}$, o investimento inicial para a instalação da central estimado é de $\mathrm{R} \$ 1.301 .508,53$. 0 preço para substituição dos motores foi estimado em R\$310.926,51 em 2026 (ano 8) e $\mathrm{R} \$ 189.288,72$ em 2034 (ano 16), já corrigidos ao valor presente. De acordo com os resultados obtidos, 0 empreendimento se paga no ano de 2032 (ano 14), ou seja, em que o VPL é superior a 0 . Com a substituição dos motores dois anos depois, o fluxo de caixa volta a ser negativo, contudo, logo retornando a registrar lucro em 2035 
(ano 17). Assim, o empreendimento mostra-se viável à luz do cenário traçado.

É importante salientar o papel da Resolução Normativa no 482/2012 (ANEEL, 2012) e sua revisão, a Resolução Normativa no 687/2015 (ANEEL, 2015). De acordo com as resoluções, a energia ativa injetada pela unidade consumidora com microgeração ou minigeração distribuída pode se converter em créditos junto à distribuidora local, sendo posteriormente compensada com o consumo de energia elétrica pelo sistema (Pin et al., 2018; Santos et al., 2018), uma vez que a venda pela tarifa do mercado cativo não seria capaz de viabilizar o empreendimento. Dessa maneira, o contexto de aplicação das resoluções atua como instrumento fundamental de auxílio na viabilidade deste tipo de empreendimento.

\section{Conclusões}

Este estudo apresentou a produção estimada do metano e a possibilidade de seu aproveitamento energético através do tratamento de efluentes líquidos em reator UASB no município de Itaúna-MG para o período de 20 anos, a partir de 2018. A vazão média do metano obtido foi de 1.899,4 $\mathrm{m}^{3}$.dia-1, sendo assim ao final de 20 anos a energia gerada alcançou os valores de 39,3 GWh.

Para o cálculo dos investimentos, foram considerados a obtenção das seguintes tecnologias: gasômetro, queimador, compressor e motores. Desta forma, o custo total do investimento foi de $R \$ 1.301 .508,53$, viabilizando a implementação do projeto no município.

Com base nos resultados obtidos, o empreendimento se paga no ano de 2032 (ano 14). Considerando a substituição dos motores logo após dois anos, o fluxo de caixa volta a ser negativo, contudo, retornando a registrar lucro em 2035 (ano 17). Desta forma, o empreendimento mostra-se viável em conformidade com o cenário traçado.

A energia produzida através do tratamento de efluentes possibilita redução dos impactos ambientais devido ao uso de uma energia limpa. Essa energia gerada permite reutilização no sistema, reduzindo assim a demanda de energia proveniente da rede. Assim o estudo mostrou que o uso de reator UASB pode ser uma forma econômica e sustentável num processo de tratamento de efluentes como no caso do município estudado.

\section{Agradecimentos}

Os autores agradecem à Coordenação de Aperfeiçoamento do Ensino Superior (CAPES) e ao Conselho Nacional de Desenvolvimento Científico e Tecnológico (CNPq), pela concessão de auxílio e pelo apoio para realização deste trabalho.

\section{Conflitos de interesse}

Os autores declaram não haver conflitos de interesse.

\section{Referências}

ABNT - Associação Brasileira de Normas Técnicas. NBR 9649: Projeto de redes coletoras de esgoto sanitário. Rio de Janeiro: ABNT, 1986.

ANEEL - Agência Nacional de Energia Elétrica. Resolução Normativa no 482, de 17 de abril de 2012. Disponível em: <http://www2.aneel.gov.br/cedoc/pubren2 012482.pdf>. Acesso em: 11 jun. 2018.

ANEEL-Agência Nacional de Energia Elétrica. Resolução Normativa no 687 , de 24 de novembro de 2015. Disponível em: <http://www2.aneel.gov.br/cedoc/pubren2 015687.pdf>. Acesso em: 11 jun. 2018.

BACEN - Banco Central do Brasil. Portal de Dados Abertos. 2018. Disponível em: <https://dadosabertos.bcb.gov.br/>. Acesso em: 11 jun. 2018. 
CETESB - Companhia Ambiental do Estado de São Paulo. Biogás: geração e uso energético efluentes e resíduo rural - versão 1.0. São Paulo, 2006. Disponível em: <http://cetesb.sp.gov.br/biogas/softwares/> . Acesso em: 16 maio 2018.

Chernicharo, C. A. L. Post-treatment options for the anaerobic treatment of domestic wastewater. Reviews in Environmental Science and Bio/technology, v. 5, n. 1, p. 7392, 2006. https://doi.org/10.1007/s11157005-5683-5

Chernicharo, C. A. L. Reatores anaeróbios. 2. ed. Belo Horizonte: DESA/UFMG, 2011.

Gouveia, N. Resíduos sólidos urbanos: impactos socioambientais e perspectiva de manejo sustentável com inclusão social. Ciência e Saúde Coletiva, v. 17, n. 6, p. 15031510, 2012. https://doi.org/10.1590/S141381232012000600014

IBGE - Instituto Brasileiro de Geografia e Estatística. Portal de mapas do IBGE: Organização do Território. 2016. Disponível em: <https://portaldemapas.ibge.gov.br/ portal.php\#homepage $>$. Acesso em: 28 mar. 2018.

IBGE - Instituto Brasileiro de Geografia e Estatística. Séries históricas. 2010. Disponível em: <https://www.ibge.gov.br/ estatisticas-novoportal/sociais/populacao/ 9662-censo-demografico-2010.html?\&t= series-historicas>. Acesso em: 28 mar. 2018.

Silveira Filho, A. S. L.; Mensah, J. H. R.; Battiston, K. M.; Barros, M. S.; Santos, I. F. S. Dimensionamento de um reator UASB para tratamento de efluentes domésticos e recuperação do biogás para produção energética: Um estudo de caso em Pouso Alegre. Revista Brasileira de Energias Renováveis, v. 7, n. 1, p. 77-94, 2018. https://doi.org/10.5380/rber.v7i1.57970

Pin, B. V. R.; Barros, R. M.; Lora, E. E. S.; Santos, I. F. S. Waste management studies in a Brazilian microregion: GHG emissions balance and LFG energy project economic feasibility analysis. Energy Strategy Reviews, $\quad$ v. $19, \quad$ p. $31-43,2018$. https://doi.org/10.1016/j.esr.2017.11.002

Qasin, S. R. Wastewater treatment plants: Planninng design and operation. 2. ed. Lancaster: Technomic Publishing Company, 1999.
Rosa, A.; Chernicharo, C. A. L.; Lobato L. C. S.; Silva, R. V.; Padilha, R. F.; Borges, J. M. Assessing the potential of renewable energy sources (biogas and sludge) in a full-scale UASB-based treatment plant. Renewable Energy, v. $124, \quad$ p. $21-26,2018$. https://doi.org/10.1016/j.renene.2017.09.0 25

Santos, I. F. S.; Barros, R. M.; Tiago Filho, G. L. Electricity generation from biogas of anaerobic wastewater treatment plants in Brazil: An assessment of feasibility and potential. Journal of Cleaner Production, v. 126 , p. 504-514, 2016. https://doi.org/ 10.1016/j.jclepro.2016.03.072

Santos, I. F. S.; Vieira, N. D. B.; Nóbrega, L. G. B. Assessment of potential biogas production from multiple organic wastes in Brazil: Impact on energy generation, use, and emissions abatement. Resources, Conservation and Recycling, v. 131, p. 54-63, 2018. https://doi.org/10.1016/ j.resconrec.2017.12.012

Scarlat, N.; Dalleman, J.-F.; Fahl, F. Biogas: Developments and perspectives in Europe. Renewable Energy, v. 129, Part A, p. 457-472, 2018. https://doi.org/10.1016/ j.renene.2018.03.006

SNIS - Sistema Nacional de Saneamento Ambiental. Série histórica. 2017. Disponível em: <http://app3.cidades.gov.br/serie Historica/>. Acesso em: 28 mar. 2018.

SNIS - Sistema Nacional de Saneamento Ambiental. Diagnóstico dos serviços de água e esgotos - 2016. Brasília: SNSA/MCIDADES, 2018.

Stazi, V.; Tomei, M. C. Enhancing anaerobic treatment of domestic wastewater: State of the art, innovative technologies and future perspectives. Science of The Total Environment, $\quad$ v. 635, p. 78-91, 2018. https://doi.org/10.1016/j.scitotenv.2018.04. 071

UN WATER - United Nations Water. Relatório mundial das Nações Unidas sobre o desenvolvimento dos recursos hídricos, 2017: Águas residuais: o recurso inexplorado, fatos e números. Disponível em: <http://unesdoc.unesco.org/images/0024/0 02475/247553f.pdf>. Acesso em: 27 mar. 2018. 
Von Sperling, M. Introdução à qualidade das águas e ao tratamento de esgotos. 3. ed. Belo Horizonte: DESA/UFMG, 2005. (Princípios do tratamento biológico de águas residuárias, 1 ).

(CC) Informação da Licença: Este é um artigo Open Access distribuído sob os termos da Licença Creative Commons Attribution, que permite uso irrestrito, distribuição e reprodução em qualquer meio, desde que a obra original seja devidamente citada. 